\title{
La pandemia covid -19 y su impacto sobre el riesgo país del Ecuador.
} Un análisis coyuntural en el periodo 2020

\author{
Mayra Lucía Reyes Pacheco \\ mayrar@uhemisferios.edu.ec \\ https://orcid.org/0000-0002-3520-1510 \\ Facultad de Ciencias Económicas y Empresariales \\ Universidad Hemisferios \\ (Quito-Ecuador) \\ Paúl Vladimir Valencia Narváez \\ pvvalencian@profesores.uhemisferios.edu.ec \\ https://orcid.org/0000-0001-8893-2512 \\ Facultad de Ciencias Económicas y Empresariales \\ Universidad Hemisferios \\ (Quito-Ecuador)
}

\section{RESUMEN}

La COVID-19 enfermedad de carácter pandémico producida por un tipo de virus llamado SARS-CoV-2 descubierto como su primera sepa en China en la ciudad de Wujhan a finales del 2019, pandemia que ha afectado negativamente en la economía mundial. El objetivo de este estudio fue analizar el impacto económico y coyuntural de la pandemia COVID-19 en la economía ecuatoriana focalizando el estudio en el indicador económico Riesgo País. El estudio se sustenta en la data obtenida por el Banco Central del Ecuador (BCE) y el Coronavirus Resource Center de la Universidad Johns Hopkins University, centro especializado en la recolección de datos científicos para investigación a nivel mundial. Se desarrolló una investigación de tipo cuantitativa y cualitativa direccionada al análisis de casos de COVID-19 y el Riesgo País basándola en regresiones lineales, exponenciales y polinómicas, así como también un análisis correlacional. Se demostró el impacto de la COVID-19 en el Riesgo País, evidenciándose, entre otros aspectos, la complejidad de una gestión oportuna de carácter gubernamental, económica y de salud ante los impactos negativos de la pandemia. Los autores basados en esta investigación generaron un análisis coyuntural de la realidad ecuatoriana en el contexto pandémico en el 2020, con la finalidad de generar herramientas de análisis de información que permitan tomar decisiones oportunas y estratégicas para minimizar impactos no favorables por la COVID-19.

Palabras clave: dolarización; pandemia covid-19; PIB; balanza comercial, riesgo país 


\title{
The covid -19 pandemic and its impact on the country risk of Ecuador.
}

\section{A conjunctural analysis in the 2020 period}

\begin{abstract}
The COVID 19 pandemic disease produced by a type of virus called SARS-CoV-2 discovered as its first known in China in the city of Wujhan at the end of 2019, that affected negatively in the world economy. The objective of this study was to analyze the economic and conjunctural impact of the COVID-19 pandemic on the Ecuadorian economy, focusing the study on the economic indicator Country Risk Rate. The study is based on data obtained by the Central Bank of Ecuador (BCE) and the Coronavirus Resource Center of the Johns Hopkins University, a center specialized in the collection of scientific data for research worldwide. A quantitative and qualitative research was developed aimed at the analysis of COVID-19 cases and Country Risk Rate, based on linear, exponential and polynomial regressions as well as a correlational analysis. The impact of COVID-19 on Country Risk Rate was demonstrated, evidencing, among other aspects, the complexity of a timely governmental, economic and health management in the face of the negative impacts of the pandemic. The authors based on this research generated a conjunctural analysis of the Ecuadorian reality in the pandemic context in 2020 , in order to generate information analysis tools that allow making timely and strategic decisions to minimize unfavorable impacts from COVID-19.
\end{abstract}

Keywords: dollarization; covid-19 pandemic; gdp; trade balance, country risk rate

Artículo recibido: 02 noviembre. 2021 Aceptado para publicación: 28 noviembre 2021 Correspondencia: santiagou@uhemisferios.edu.ec Conflictos de Interés: Ninguna que declarar 


\section{INTRODUCCIÓN}

El Riesgo País es un indicador que mide las posibilidades de pago de la deuda externa de un país, este cálculo se lo realiza por medio del Indicador de Bonos de Mercados Emergentes- EMBI (Diferencia de tasa de interés que pagan los bonos denominados en dólares, emitidos por países subdesarrollados y los bonos del Tesoro de Estados Unidos, considerados "libres" de riesgo), creado por la firma internacional JP Morgan Chase. Mientras más alto es el valor del Riesgo País, más crecen las tasas de interés a la hora de endeudarse, y puede repercutir negativamente en inversiones extrajeras y en las nuevas operaciones crediticias, tanto para empresas públicas como para privadas, sin embargo, si el índice es bajo puede atraer a los inversores y contribuir con el desarrollo de los países como comentan (Sánchez, Vayas, Mayorga, \& Freire, 2021).

El COVID-19 afectó a nivel mundial a pequeñas empresas, y Ecuador no está exento de ello, la principal causa es que las mismas no contaban con ingresos suficientes o su nivel de endeudamiento estaba colapsado. El estado de excepción y las consecuentes restricciones de movilidad y horarios de trabajo llevaron a las pequeñas empresas a reducir sus ingresos y cerrar sus puertas, por otro lado, las empresas grandes y más sólidas tuvieron una reducción de ingresos y en consecuencia la reducción de sueldos y colaboradores. (Bernal, Burgos Salazar, Solórzano, \& Cantos)

La ciudadanía se vio afectada ya que los precios de los productos de primera necesidad se vieron incrementados hasta el 50\%. Así las empresas de productos alimenticios tuvieron un ingreso económico elevado mientras que las empresas de productos de segunda necesidad vieron reducido su flujo. Ejemplo de ello en un rubro importante en la línea de exportación no tradicional es el campo florícola, en esta línea se encuentran fïncas productoras, agencias de carga, comercializadoras, obtentores y operadoras logísticas. Estamos frente a una reestructuración de las mismas ya que las condiciones son inestables consecuencia de la reducción de exportaciones además de la reducción de un $40 \%$ en el precio.

Como lo mencionan (Castro, Castañeda, Ruiz Molina, González, \& Poveda Burgos) dentro de los procesos de reestructuración empresarial que se vive en las empresas productoras y exportadoras de flores ente la crisis internacional producto de la pandemia causada por el COVID-19, las condiciones de trabajo en el sector se han vuelto inestables por cuanto ante la reducción de las exportaciones y esto sumado a un precio del $40 \%$ por 
debajo del precio habitual del producto es un futuro incierto y preocupante a miles de trabajadores vinculados de manera directa e indirecta al sector. La oferta y demanda que se vive en los mercados internacionales está ocasionando ingentes pérdidas económicas al sector florícola ecuatoriano, pues según datos del Banco Central del Ecuador, además de los efectos a causa del COVID-19 hay que añadir también una caída de precios en el mercado internacional, altos costos de producción, mal clima, crisis económica en los países de destino y la falta de competitividad de Ecuador.

Las empresas en todos los campos están viéndose obligadas a reevaluar toda su planificación estratégica. Definir nuevos objetivos, canales de comercialización y distribución, basado en un escenario económico cambiante y dependiente de la evolución de COVID-19.

Es evidente que el Ecuador al ser un país con muchas oportunidades de crecimiento económico, lamentablemente no es correspondido. Una crisis en donde se combinan a creciente dependencia extractivista y el consiguiente peso de una matriz productiva primario exportador; los elevados niveles de concentración de mercados, finanzas y riqueza; el aumento del desempleo y la pobreza (con mayor énfasis en las zonas rurales y campesinas); el sostenimiento de la liquidez interna (en especial del sector fiscal) vía endeudamiento externo agresivo (...) (Acosta, 2020)

El BM también estima escenarios positivos para el 2021 y 2022, con un crecimiento del $3,2 \%$ y $1,5 \%$ respectivamente. Pese a ello, este panorama de recuperación para los próximos años estaría condicionado por factores coyunturales significativos que afectan a la economía y el financiamiento público. Estos factores son el desplome del precio del petróleo, la reducción de las exportaciones, la disminución de llegada de turistas internacionales, y la reducción de las remesas provenientes del exterior. Tomando como referencia los datos del Banco Interamericano de Desarrollo (BID), en Ecuador, la crisis ocasionada por el COVID-19 puede generar una pérdida de hasta 460.000 empleos formales, aunque esto dependerá de cómo evolucione la pandemia y de las medidas de mitigación tomadas por el gobierno, resalta la entidad internacional. Luego de una década de reducción de la pobreza en el país (36,7\% a 21,5\%), en los últimos dos años, la pobreza se ha incrementado, evidenciando un aumento de 3,5 puntos porcentuales de 2017 a 2019. La aparición del COVID-19, profundiza de mayor manera este problema social, ya que afecta con mayor fuerza a la población en situación de vulnerabilidad. Según datos de la 
Encuesta Nacional de Empleo, Desempleo y Subempleo (ENEMDU) a diciembre de 2019; el 80\% de los pobres trabajan en el sector informal, el 89\% se encuentran en empleo inadecuado y el 64\% laboran principalmente como trabajadores no calificados, trabajadores de los servicios, comerciantes, oficiales operarios, artesanos y en ocupaciones elementales, actividades que en su mayoría no se pueden ejercer debido a las medidas de distanciamiento social dictadas por el gobierno nacional. (Correa, Izquierdo Montoya, \& García Vélez, 2020)

Haciendo referencia al impacto del COVID-19 en la economía ecuatoriana, uno de los sectores más sacudido es el sector exportador, en este punto es importante resaltar que, el comercio internacional representa un factor primordial para el país, pues los ingresos percibidos por la nación son altamente dependientes de las exportaciones de productos. En torno a esto, (Macas, 2016) ha expresado que en materia economía internacional, Ecuador depende de cuatro productos básicos, a saber, petróleo, banano, frutos del mar y flores, y que a decir de (Luna, 2017) suman siempre más del 75\% de las ventas totales. Este volumen de exportaciones va dirigido principalmente a los mercados de China, Europa y Estados Unidos como así lo comenta (Vásquez Lafebre, Quevedo Vásquez, Prado Pinzón, \& Quevedo Barros, 2020).

En las últimas dos décadas existen varios acontecimientos que marcaron la realidad actual, como son el fenómeno El Niño en 1998, el feriado bancario en 1999, la dolarización en el 2000, la limitada productividad del petróleo en el 2002, la crisis inmobiliaria en 2008 y sus repercusiones en el precio del crudo en el 2009, el terremoto en Manabí en el 2016 y la pandemia Covid-19. Por otra parte, otros acontecimientos que suscitaron una caída preocupante en el nivel de exportaciones durante el 2002, fue el banano donde existió caída de precios y estancamiento en la demanda internacional, mientras en el camarón la presencia de plagas y problemas ambientales intervinieron en el rendimiento de la producción, la baja inversión en el sector petrolero solo aprovechaba la mitad de capacidad instalada. La crisis inmobiliaria internacional y su impacto a nivel mundial provocó volatilidad del precio del petróleo. (Ordóñez, Campuzano Vásquez, Vega Jaramillo, \& Luna Romero, 2020)

La volatilidad de los indicadores económicos a nivel país siempre han sido afectados por las crisis socioeconómicas internacionales generando estancamiento en los crecimientos económicos acompañado de tensiones sociales. Por tal razón, el análisis de los casos de 
contagio de COVID-19 y uno de los principales indicadores macroeconómicos como es el Riesgo País, se pretende en este artículo determinar el si en efecto ¿existe un alto grado de influencia y correlación parametrizada a través de modelos matemáticos entre el Riesgo País y el COVID-19? Por esta razón, el objetivo de esta investigación es analizar la correlación de la pandemia COVID-19 y el Riesgo país como indicador macroeconómico trascendental en la economía ecuatoriana.

\section{METODOLOGÍA}

La metodología que se expone en este trabajo corresponde a un enfoque cuantitativo y cualitativo. En el campo cuantitativo se han aplicado los métodos de regresión lineal simple, regresión exponencial y regresión polinómica, de igual manera se ha aplicado un análisis de correlación donde se toma como variables al Riesgo País basada en datos históricos estadísticos y económicos del Banco Central del Ecuador y los casos de COVID-19 presentados en Coronavirus Resource Center de la Universidad Johns Hopkins University durante el periodo enero a diciembre 2020, con lo que se busca analizar el impacto de la COVID-19 en el Riesgo País tomando en cuenta un análisis coyuntural de la realidad ecuatoriana en el contexto pandémico en el 2020 cumpliendo así el enfoque cualitativo en un contexto actual por COVID-19: caso Ecuador.

La Regresión Lineal puede definirse como una relación funcional entre dos o más variables correlacionadas. Se utiliza para pronosticar una variable con base en la otra. Por lo general, la relación se desarrolla a partir de datos observados. Primero es necesario graficar los datos para ver si aparecen lineales o si por lo menos partes de los datos son lineales. La regresión lineal se refiere a la clase de regresión especial en la que la relación entre las variables forma una recta. La recta de la regresión lineal tiene la forma $Y=a+$ $\mathrm{bX}$, donde $\mathrm{Y}$ es el valor de la variable dependiente que se despeja, a es la secante en $\mathrm{Y}, \mathrm{b}$ es la pendiente y $\mathrm{X}$ es la variable independiente (en el análisis de serie de tiempo, las $\mathrm{X}$ son las unidades de tiempo).La regresión lineal es útil para el pronóstico a largo plazo de eventos importantes, así como la planeación agregada según (Chase, Jacobs, \& Aquilano, 2009)

Regresión exponencial, según (Martínez De Lejarza \& Martínez de Lejarza, 1992, pág. 10)

Será aquella en la que la función de ajuste será una función exponencial del tipo $y=a \cdot b x x$ 
La regresión exponencial, aunque no es lineal es linealizable tomando logaritmos ya que haciendo el cambio de variable

$\mathrm{v}=\log \mathrm{y}$ tendremos que la función anterior nos generaría:

$\mathrm{v}=\log \mathrm{y}=\log (\mathrm{a} \cdot \mathrm{bx})=\log \mathrm{a}+\mathrm{x} \log \mathrm{b}$

la solución de nuestro problema vendría de resolver la regresión lineal entre v ý x, y una vez obtenida supuesta ésta:

$\mathrm{V}^{*}=\mathrm{A}+\mathrm{Bx}$; obviamente la solución final será:

$\mathrm{a}=\operatorname{antilog} \mathrm{A}$ y $\mathrm{b}=\operatorname{antilog} \mathrm{B}$

El método de Regresión Polinómica según (Vinueza, 2016) consiste en:

La dependencia entre la variable de respuesta y la regresora frecuentemente no es lineal. No obstante, el principio de parsimonia (navaja de Occam) requiere que ajustemos un modelo lineal simple (el más simple, menos parametrizado) como modelo nulo, a no ser que un modelo no lineal se demuestre significativamente superior al nulo.

¿Cómo determinar la significancia de la desviación del supuesto de linearidad?

Una de las maneras más sencillas es usando la regresión polinomial, donde: $\mathrm{y}=\mathrm{a}+\mathrm{bx}+\mathrm{cx} \mathrm{x}^{2}+\mathrm{dx}^{3} \ldots$

El concepto básico es sencillo. Tenemos una sola variable explicativa contínua, $\mathrm{x}$, pero podemos ajustar potencias mayores de $\mathrm{x}, \operatorname{como~}^{2}, \mathrm{x}^{3} \ldots \mathrm{y}$ añadirlas al modelo, junto a $\mathrm{x}$, para describir diversos tipos de curvatura en la relación y x. Las funciones polinomiales presentan gran flexibilidad de formas, incluso al añadir un solo término cuadrático, dependiendo de los signos de los términos lineales y cuadrático.

Otra forma de evaluar la relación entre dos variables consiste en calcular el coeficiente de correlación. Esta medida expresa el grado o la fuerza de la relación lineal (tome en cuenta que la correlación no implica necesariamente causalidad). Por lo general identificado como $\mathrm{r}$, el coeficiente de correlación puede ser cualquier número entre +1 y -1 según (Render \& Heizar, 2014)

\section{RESULTADOS}

El riesgo país mide las probabilidades de que una nación caiga en mora en sus obligaciones crediticias. Mientras más alto, más riesgoso resulta el país y, por tanto, los mercados cobran intereses más altos a esa nación cuando esta busca financiamiento y éste se ve influenciado por diferentes factores y entre ellos destacamos la pandemia del COVID-19. 
A continuación, se presenta un análisis coyuntural sobre la relación de las variables Riesgo País y evolución de Casos de COVID-19 durante el periodo enero a diciembre 2020.

Para tener una perspectiva objetiva y en una escala similar a las dos variables (Riesgo País y Casos de COVID-19) hemos normalizado los datos. Considerando como $100 \%$ el valor máximo de cada una de las variables, 212.512 casos de COVID-19 y para Riesgo País es 6063 puntos.

Figura 1. Comparativa Riesgo País vs Casos Covid-19

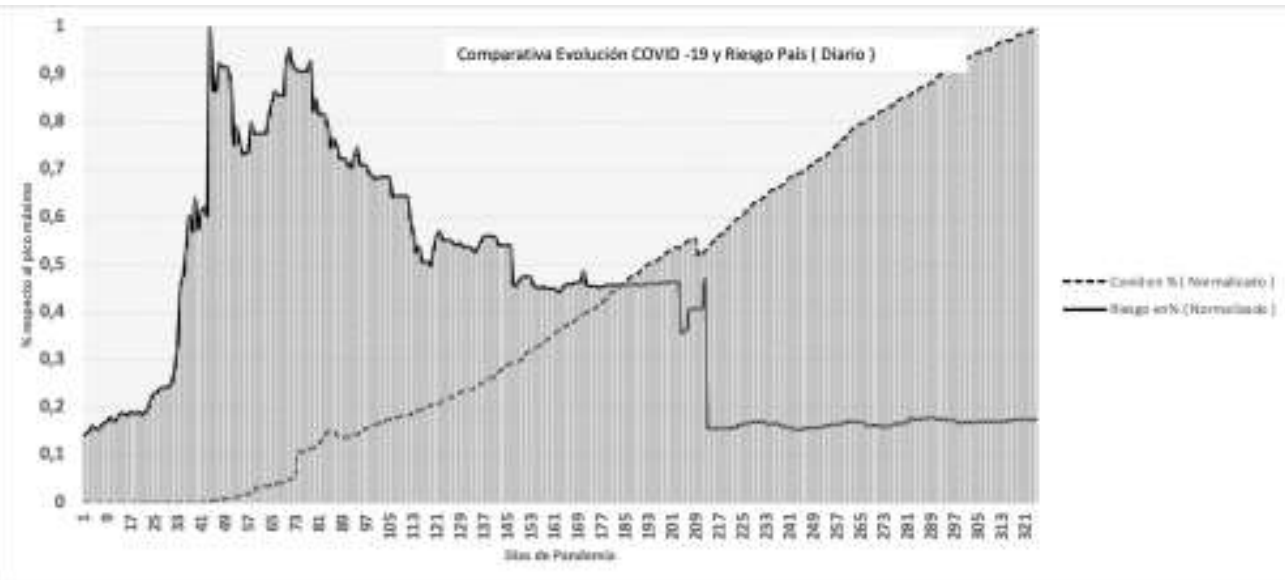

Fuente: Johns Hopkins University \& Medicine https://coronavirus.jhu.edu/map.html Banco Central Del Ecuador https://www.bce.fin.ec/index.php/informacioneconomica

\section{Elaborado por: Autores}

Al revisar la evolución de las variables de estudio se puede evidenciar que en el periodo comprendido entre los días 1 y 71 (miércoles 22 de enero de 2020 -martes 21 de abril de 2020) se evidencia la primera curva creciente del COVID-19 y su impacto directo en el Riesgo país, evidenciando uno de los picos máximos del Riesgo País al inicio del año 2020.

El 29 de febrero se confirma el primer caso de Covid-19 en el país, lo que ocasionó que en marzo el Ecuador se posicionara a la par de Argentina en el segundo puesto del país latinoamericano más riesgoso, incrementándose diariamente hasta llegar al punto máximo del año en 6063 puntos en el 23 de marzo del 2020, consecuencia de que día anterior la asamblea sugiriera al ejecutivo dejar de pagar la deuda externa para destinar esos recursos a afrontar la emergencia sanitaria.

La noche del lunes 16 de marzo, el presidente de la República, Lenín Moreno Garcés, a través de una cadena nacional, declaró el Estado de Excepción en todo el territorio ecuatoriano, con el propósito de contener la transmisión del coronavirus (COVID-19). 
(Secrataría General de la Presidencia, s.f.)

El desconocimiento del manejo del COVID-19, la población carente de información sobre el manejo de medidas preventivas y la saturación en los sistemas de salud creó incertidumbre en la economía y parálisis casi al $100 \%$ de todas las actividades productivas internas y externas, lo que influyó drásticamente a que el Ecuador entre en emergencia económica con sus acreedores extranjeros para el pago de Deuda Externa que en este momento era de \$41.055,12 millones de dólares.

Desde el día 71 (martes 21 de abril de 2020) hasta el día 162 (martes 21 de julio de 2020) el Riesgo País empieza a reducir hasta llegar a una constante de aproximadamente de 2770 puntos manteniéndose en este valor hasta el día 204 (martes 1 de septiembre de 2020).

Siendo las provincias más afectadas Guayas y Pichincha, Pichincha reportó 19.057 casos, frente a los 17.993 de Guayas. (PRIMICIAS, s.f.)

Se produce una intersección entre la evolución del Riesgo País y los Casos COVID-19 en el día 184 (miércoles 12 de agosto de 2020) siendo los valores de cruces 2772 para Riesgo País y 97110 casos de COVID-19.

Hasta el día 203 (lunes 31 de agosto de 2020) se mantiene constante la media de 2700 puntos de Riesgo País, en la semana del día 204 al 211 (martes 1 de septiembre de 2020 y martes 8 de septiembre de 2020) en la cual se producen fluctuaciones tanto en el Riesgo País como en los casos de COVID-19 cerrando esta semana con un Riesgo País de una media de 950 punto es decir una caída del 25\% correspondiente con una reducción del $5 \%$ de casos COVID-19.

Desde el 4 mayo de 2020 inicia la etapa del "Distanciamiento Social", misma que se basará en una semaforización del territorio nacional, el 29 de abril se dispuso que se reactive el sector de la construcción, siguiendo los protocolos establecidos en el "Plan Piloto de Reactivación del Sector de la Construcción en el contexto de la emergencia sanitaria por COVID-19”, el 30 de abril se autorizó la realización de los vuelos pendientes que garanticen el retorno de ciudadanos ecuatorianos y extranjeros residentes que todavía se encuentran fuera del país, a bordo de vuelos chárter contratados, el 1 de septiembre se levantan las restricciones de aforos de $30 \%$ en restaurantes y centros comerciales en el Distrito Metropolitano de Quito, los cuales se incrementarán al 50\%, de conformidad a los demás cantones con semáforo "amarillo" y además se inicia el retorno progresivo de 
labores en instituciones públicas.

El 4 de septiembre de 2020, el Ministerio de Salud informó que en la cifra que muestra el número de pacientes ya no constarán aquellos que fueron diagnosticados con una prueba rápida. Únicamente se dará a conocer a las personas que recibieron un diagnóstico positivo con un test PCR (Primicias, s.f.)

El 7 de septiembre en el boletín especial 1647 se informa del proceso exitoso de la renegociación de la deuda externa, como resultado de este histórico proceso, a cargo del Gobierno Nacional, el país logró un alivio en el pago de deuda externa por USD 16.452 millones, durante los próximos 10 años; se redujo el capital en más de USD 1.500 millones; se alcanzó un plazo a 12,7 años para el pago; la tasa de interés pasó de 9,2\% a 5,3\%; y se logró un periodo de gracia de cinco años en el capital y, prácticamente, dos años en los intereses.

A partir del 10 de septiembre el riesgo país se mantiene constante con una media de 950 puntos y la evolución del COVID-19 es creciente con una ligera tendencia a estabilizarse con una pendiente del $52 \%$.

Análisis Correlacional: Se ha realizado una correlación entre el Riesgo País y el COVID-19 con el fin de definir las aristas en las cuales se basan sus resultados, la puntuación del Riesgo País tiene un componente que se basa en la percepción de confianza del ser humano ante el posible riesgo de pérdida de valores económicos, la gráfica que a continuación se presenta nos permitirá detallar y confirmar esta aseveración:

Figura 2. Análisis de correlación Riesgo País vs Covid-19

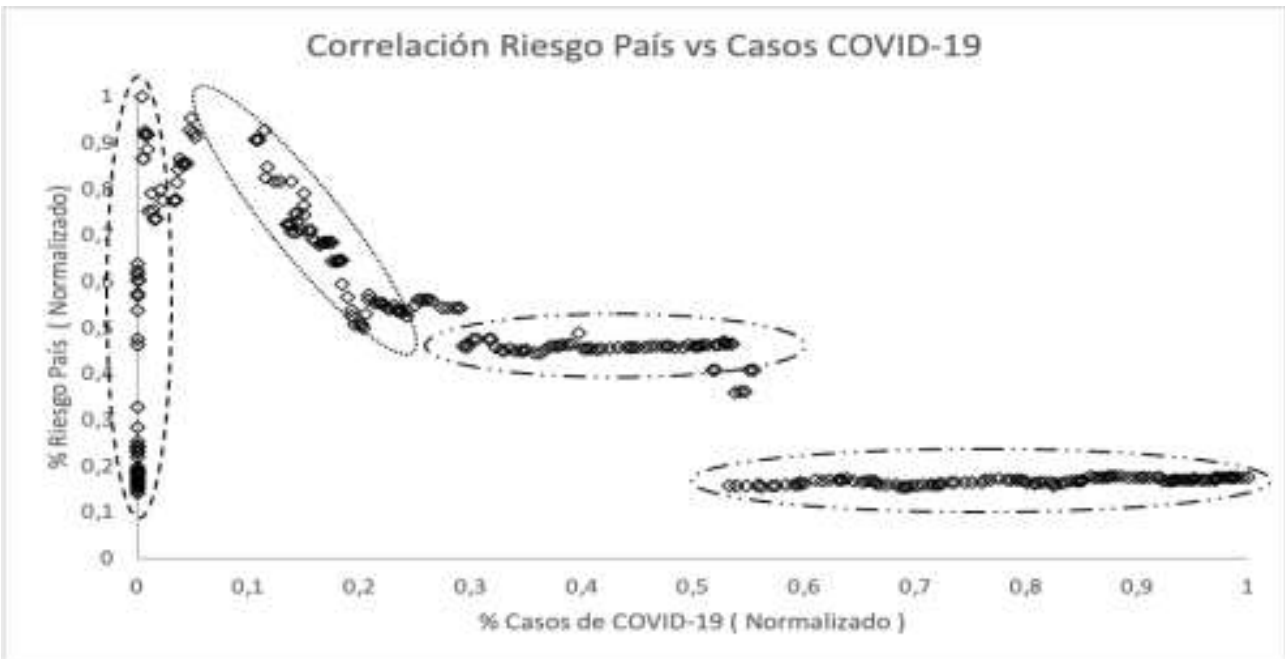

Fuente: Johns Hopkins University \& Medicine https://coronavirus.jhu.edu/map.html Banco Central Del Ecuador https://www.bce.fin.ec/index.php/informacioneconomica Elaborado por: Autores 


\section{Podemos observar tres tipos de comportamiento claramente diferenciados:}

1. Covid-19 ligeramente creciente y Riesgo País creciente

2. Covid-19 creciente y Riesgo País decreciente

3. Covid-19 creciente y Riesgo País constante

Estos 3 tipos de comportamiento se explican basados en la información y percepción del ser humano ante un elemento desconocido como es una pandemia mundial.

- Primer tipo de comportamiento (línea “-----“): Al existir desconocimiento de un fenómeno mundial que afecta a la población en general en una de las necesidades humanas básicas como es la salud, genera incertidumbre por el desconcierto ante el tratamiento, prevención y manejo del virus que en un principio se ve como amenaza letal de muerte incidiendo al miedo y pánico en la sociedad mundial, con ello la especulación, el desabastecimiento de insumos de primera necesidad y la incertidumbre financiera en mercados internacionales genera un crecimiento excesivamente acelerado de la variable macroeconómica Riesgo País que es uno de los termómetros de estabilidad política, económica y social. Este tipo de comportamiento es claramente evidenciado en el primer trimestre del 2020 en el cual se adoptaron medidas drásticas como el confinamiento, cierre de negocios, recorte de plazas laborales, cierres de planteles educativos y cierre de aeropuertos y movilidad interna.

El descenso de importaciones y exportaciones con una caída del $20 \%$ respectivamente, y el crudo WTI terminó el 1er trimestre con una caída de un $66,82 \%$, las peores bajas desde su inicio en 1983 y el PIB con una caída del -1.8 con respecto al último trimestre del 2019. (Precio Petróleo Punto.net, s.f.)

- El segundo tipo de comportamiento (línea .....*): se ve determinado por un crecimiento en los casos Covid-19 y un decrecimiento en el Riesgo País, este tipo de comportamiento es claramente palpable en la segunda mitad del T2 y la primera mitad del T3, esto se explica ya que existieron medidas de prevención y manejo del COVID19, a pesar del incremento de casos existe una gestión del gobierno y los GADS, con ello la percepción de seguridad mejora, el aparato productivo se pone en marcha. La economía empieza a moverse. Ya existen medidas de seguridad claras y concisas. Es por ello que el Riesgo País desciende. El Gobierno anuncia "la nueva normalidad" se pasa del aislamiento al distanciamiento, La medida implica la reactivación de 
sectores. "No podemos permanecer encerrados en casa", dijo Romo; sin embargo, enfatizó que esta nueva etapa no implicará un regreso a la vida como se conocía antes de la llegada de la pandemia del covid-19 al Ecuador. "No significa que vamos a volver a lo que era enero o lo que era febrero. Es una nueva normalidad lo que vamos a tener después del coronavirus. Las cosas se harán de forma muy paulatina“, dijo la Ministra, quien puntualizó que el presidente Lenin Moreno, al final de la tarde de este 24 de abril del 2020, anunciará los detalles, horarios y acciones que se van a emprender en esta nueva etapa para combatir el coronavirus. (EL COMERCIO, 2020)

- El tercer tipo de comportamiento (línea “-.....”): refleja un aumento de casos COVID, y una estabilidad el riesgo país, esto se explica con las medidas tomas por el gobierno central y los GADS que consiguen un escenario invariable de casos de Covid-19 es decir siguen en un crecimiento constante sin embargo no se dan grandes picos ni de subida ni de bajada, esto se refleja desde finales de T3 y T4. Desde el COE Nacional se menciona que en Septiembre se tiene tasas de mortalidad más bajas en la región, y tras 180 días de medidas restrictivas se elimina el estado de excepción, en Octubre se implementa medidas de reactivación del aparato productivo como por ejemplo regulaciones en el aforo de personas para los establecimientos públicos, Noviembre las farmacéuticas informan sobre la efectividad de las vacunas, estos eventos suscitados en el T3 y T4 permitieron generar un PIB considerable en el T3 del 25\% del total del PIB equivalente a \$ 24’166.757 millones de dólares y en el T4 el 23\% que equivale a $\$ 22^{\prime} 619.920$ millones de dólares, esto permite evidenciar que en el T3 con las medidas adoptadas en cuanto a la apertura del comercio en los diferentes ámbitos empresariales permitió una recuperación económica a nivel de país lo que impactó directamente a generar una estabilidad del Riesgo País con una media de 1035 puntos. 
Figura 3. Análisis de crecimiento porcentual en el 2020 de Casos Covid-19

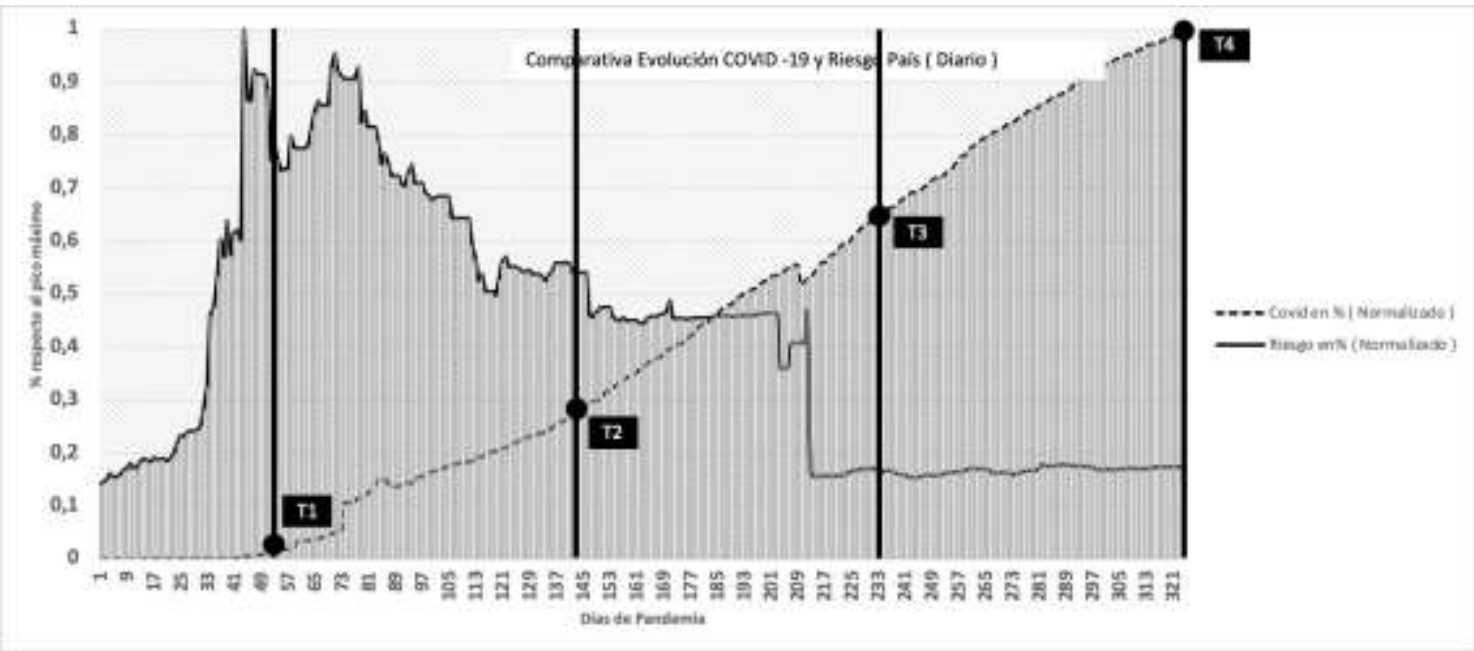

Fuente: Johns Hopkins University \& Medicine https://coronavirus.jhu.edu/map.html Banco Central Del Ecuador https://www.bce.fin.ec/index.php/informacioneconomica

Elaborado por: Autores

La gráfica anterior nos permite analizar el incremento trimestral de los casos COVID-19 en el Ecuador.

\section{Tabla 1}

Porcentajes de casos de COVID-19 trimestrales y acumulado

\begin{tabular}{lcc} 
Trimestre & \% Trimestral & \% Acumulado \\
\hline T1 & $2 \%$ & $2 \%$ \\
\hline T2 & $26 \%$ & $28 \%$ \\
\hline T3 & $37 \%$ & $65 \%$ \\
\hline T4 & $35 \%$ & $100 \%$
\end{tabular}

Fuente: Johns Hopkins University \& Medicine https://coronavirus.jhu.edu/map.html Banco Central Del Ecuador https://www.bce.fin.ec/index.php/informacioneconomica Elaborado por: Autores

En el T2 hay un incremento del 26\% de casos de Covid con respecto al T1, mientras que en el T3 hay un incremento del $37 \%$ con respecto al T2 y el T4 el incremento de casos de Covid-19 es del 35\% con respecto al T3. 
Figura 4. Análisis de fluctuación porcentual del Riesgo País en el 2020

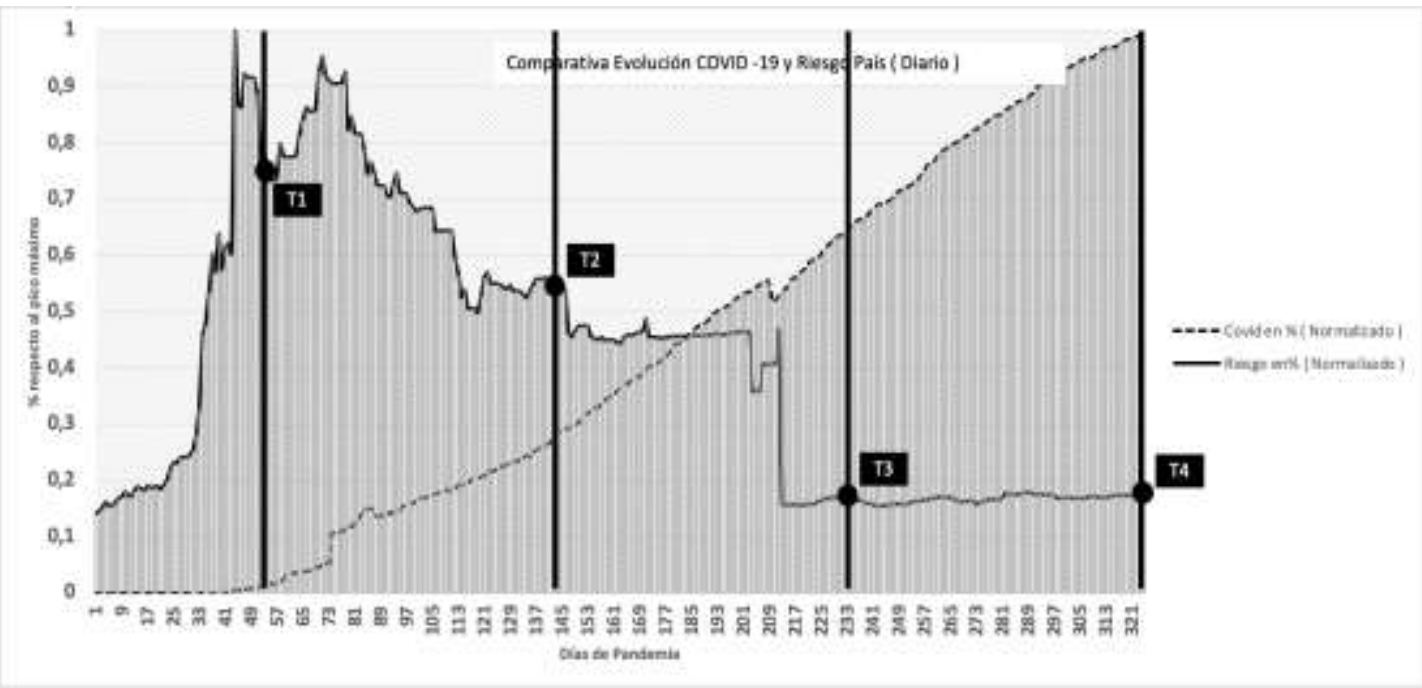

Fuente: Johns Hopkins University \& Medicine https://coronavirus.jhu.edu/map.html Banco Central Del Ecuador https://www.bce.fin.ec/index.php/informacioneconomica Elaborado por: Autores

La gráfica anterior nos permite analizar la fluctuación trimestral del Riesgo País en el Ecuador en el año 2020.

\section{Tabla 2}

Porcentajes de variación Riesgo País

\begin{tabular}{ccc}
\hline Trimestre & $\begin{array}{c}\text { Rangos Trimestrales } \\
\text { (Apertura y Cierre) }\end{array}$ & $\begin{array}{c}\text { \% Respecto al pico } \\
\text { máximo (6063) }\end{array}$ \\
\hline T1 & $852-4553$ & $14 \%-75 \%$ \\
\hline T2 & $4783-3373$ & $78 \%-55 \%$ \\
\hline T3 & $3278-1015$ & $54 \%-16 \%$ \\
T4 & $989-1062$ & $16 \%-17 \%$
\end{tabular}

Fuente: Johns Hopkins University \& Medicine https://coronavirus.jhu.edu/map.html Banco Central Del Ecuador https://www.bce.fin.ec/index.php/informacioneconomica

\section{Elaborado por: Autores}

En el T1 hay una variación del $61 \%$ de puntos en el Riesgo País, con respecto al pico máximo, en el T2 se evidencia una variación del 23\%, en el T3 existe una variación del $38 \%$ y mientras que en el T4 es prácticamente estable con una variación del 1\%.

El T1 cierra COVID-19 con 2240 casos y el Riesgo País con 4553 puntos, éste último representa el $75 \%$ del pico máximo del $\mathrm{T} 1$, se explica porque los casos empiezan casi a 
mediados de marzo con un desconociendo total de la población así como de su tratamiento y reacción operativa del COE Nacional.

Figura 5. Comparativa evolución COVID-19 VS Riesgo País (T1)

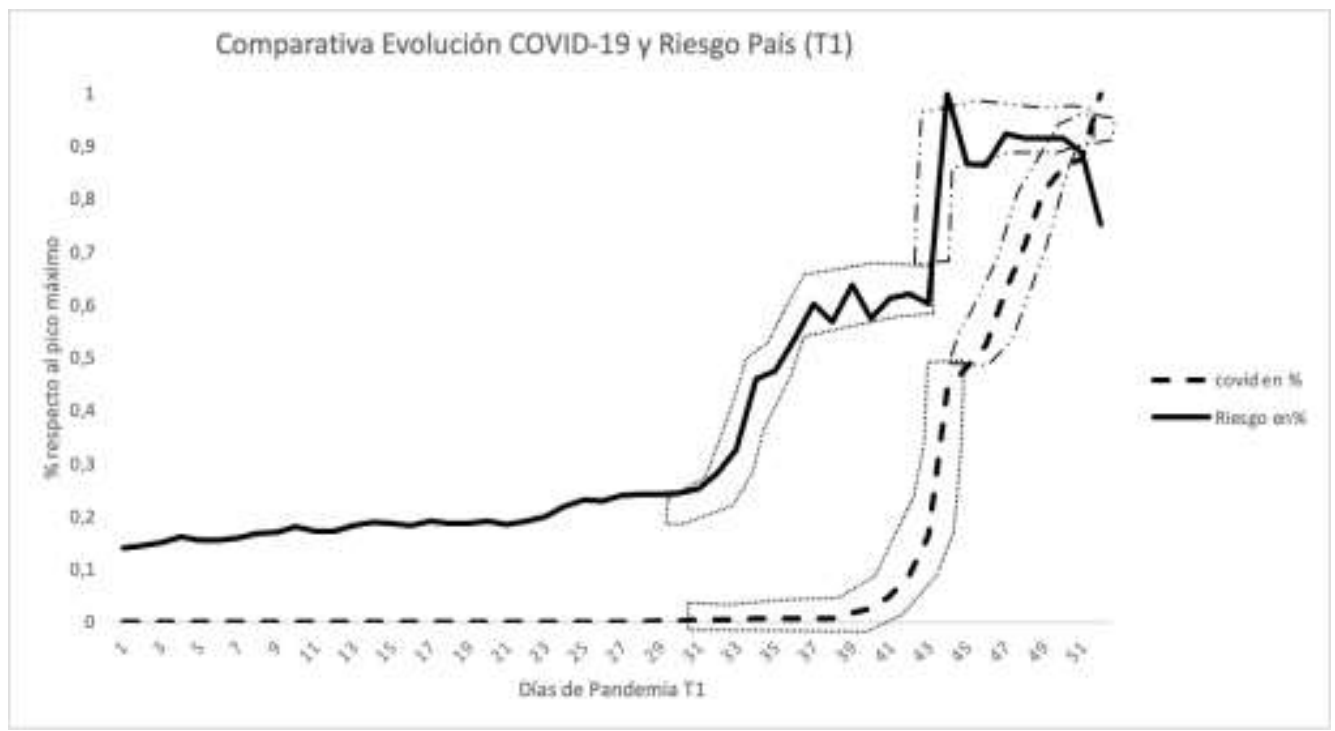

Fuente: Johns Hopkins University \& Medicine https://coronavirus.jhu.edu/map.html

Banco Central Del Ecuador https://www.bce.fin.ec/index.php/informacioneconomica

\section{Elaborado por: Autores}

Podemos mirar en la gráfica dos zonas claramente identificadas, línea (“--.-”) y (“-..-..”) Zona 1 (línea “---”): En esta zona la primera meseta, Riesgo País, refleja un incremento de $37 \%$ hasta el dato \#43 (día 20 de marzo), coincidente con la primera rampa de evolución del COVID-19 con un 43\% de incremento. Se puede notar que la relación es directa entre estas dos variables en el T1, a mayor casos de COVID-19 se va incrementando el Riesgo País.

Zona 2 (línea “-.....”): En esta zona existe de igual forma una coincidencia en la variación de pendientes tanto en la curva de COVID-19 del 47\% y la curva de Riesgo País con el $28 \%$ de incrementos.

Esta variación de tendencias es congruente con la primera semana de confinamiento en el País, que fue a partir del 16 de marzo del 2020. 


\section{Figura 6.}

Determinación de Curvas de Tendencias T1

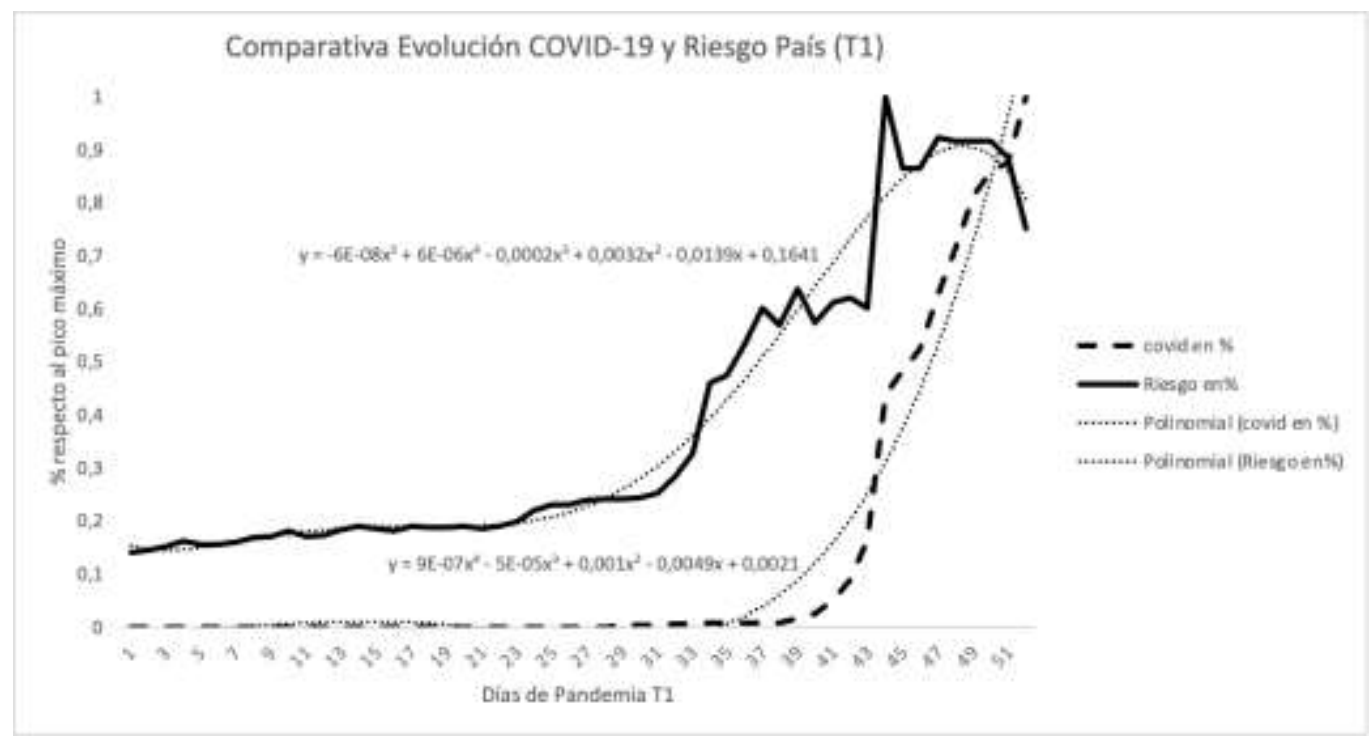

Fuente: Johns Hopkins University \& Medicine https://coronavirus.jhu.edu/map.html

Banco Central Del Ecuador https://www.bce.fin.ec/index.php/informacioneconomica

Elaborado por: Autores

El análisis matemático de las curvas de evolución de Riesgo País y COVID 19 en el T1 arrojan ecuaciones de 5to y 4to grado respectivamente siendo:

\section{Ecuación de Curva de Tendencia de Riesgo País T1}

$y=-6 E-08 x^{5}+6 E-06 x^{4}-0,0002 x^{3}+0,0032 x^{2}-0,0139 x+0,1641$

\section{Ecuación de Curva de Tendencia de COVID-19 T1}

$y=9 E-07 x^{4}-5 E-05 x^{3}+0,001 x^{2}-0,0049 x+0,0021$

El T2 se evidencia un crecimiento del $25 \%$ del COVID-19 y el Riesgo País se coloca 55\% sobre el pico máximo que en cifras representan 56432 casos COVID-19 y 3373 puntos de Riesgo País al cierre del trimestre T2, explicado con la teoría anteriormente mencionada sobre comportamiento, identificamos 6 zonas claramente identificadas: 


\section{Figura 7}

Comparativa evolución COVID-19 VS Riesgo País (T2)

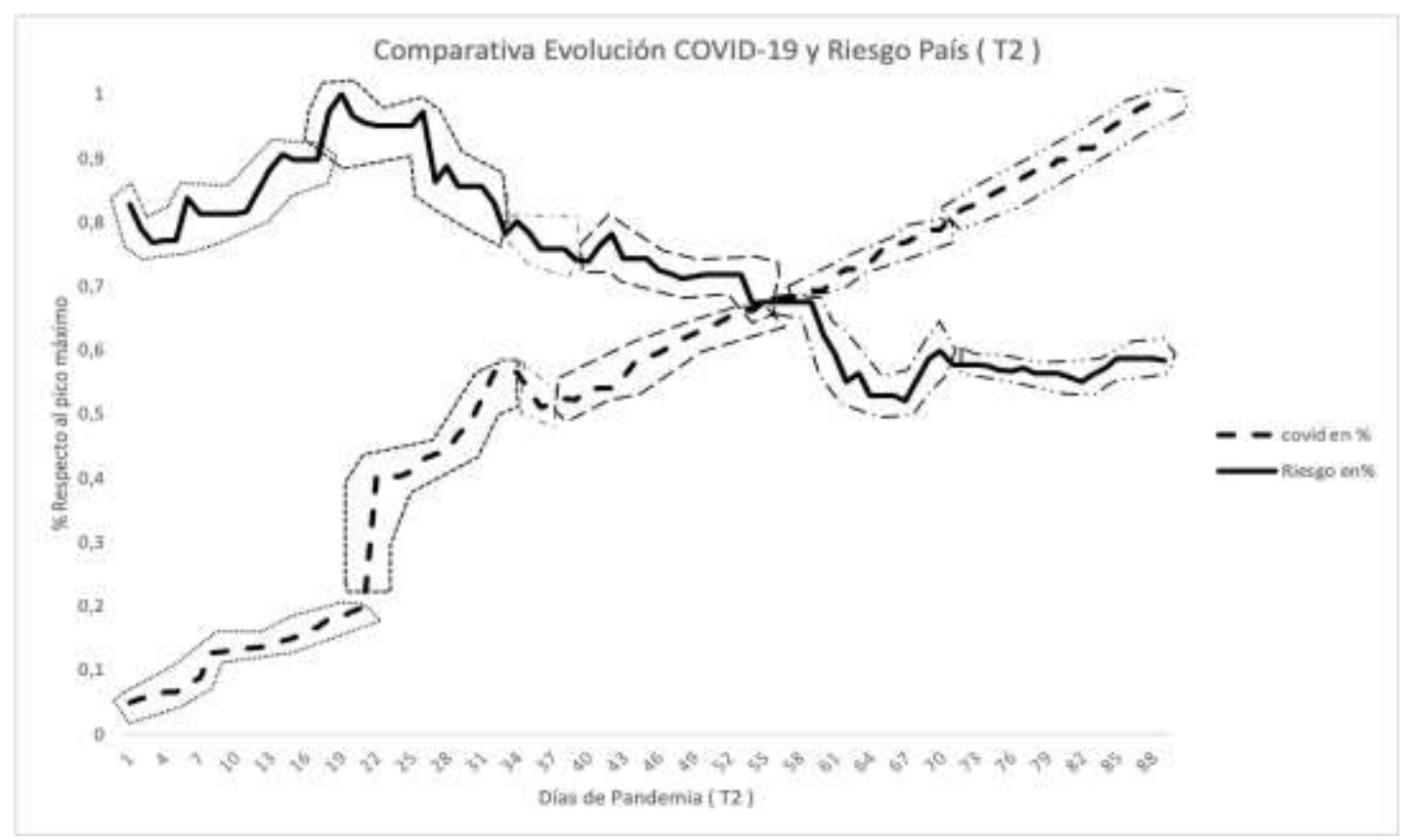

Fuente: Johns Hopkins University \& Medicine https://coronavirus.jhu.edu/map.html

Banco Central Del Ecuador https://www.bce.fin.ec/index.php/informacioneconomica

Elaborado por: Autores

Zona 1 (línea “........”)

La zona morada hasta el dato 22 (día 24 de abril) presenta una tendencia homogénea tanto de crecimiento de Riesgo País como de COVID-19, teniendo un crecimiento del Riesgo País del 7\% y del COVID del 15\% en relación al punto máximo.

Zona 2 (línea “---------")

La zona verde hasta el dato 34 (día 6 de mayo) evidencia una tendencia de decrecimiento del Riesgo País con el 11\% teniendo como valor en la meseta del 95\% respecto al punto máximo, mientras que la variable COVID-19 tiene un crecimiento del 37\%.

Zona 3 (línea “"-.-.-.-.")

La zona amarilla hasta el dato 38 (10 de mayo) se observa que existe un decrecimiento del COVID-19 del 5\% y del Riesgo País del 3\% en relación al punto máximo.

Zona 4 (línea “" $\ldots$ - “)

La zona gris hasta el dato 58 ( 27 de mayo) el Riesgo País baja un 4\% y el COVID-19 tiene un crecimiento lineal del $18 \%$ en relación al punto máximo.

Zona 5 (línea “_._-_._._.”) 
La zona celeste presenta en el dato 70 ( 11 de junio) se aprecia un decrecimiento atípico del Riesgo País no coincidente con un incremento sostenido de casos de COVID-19. El Riesgo País evidencia un decrecimiento del $8 \%$ y un crecimiento de los casos de COVID19 en un $9 \%$.

Zona 6 (línea “._._.._.._.....")

En la zona lila en el dato 89 ( 30 de junio) existe una estabilización del Riesgo País con un crecimiento lineal de los casos del COVID-19 que tiene un crecimiento del $22 \%$ y el Riesgo País presenta una ligera reducción de apenas el $1 \%$.

\section{Figura 8}

Determinación de Curvas de Tendencias T2

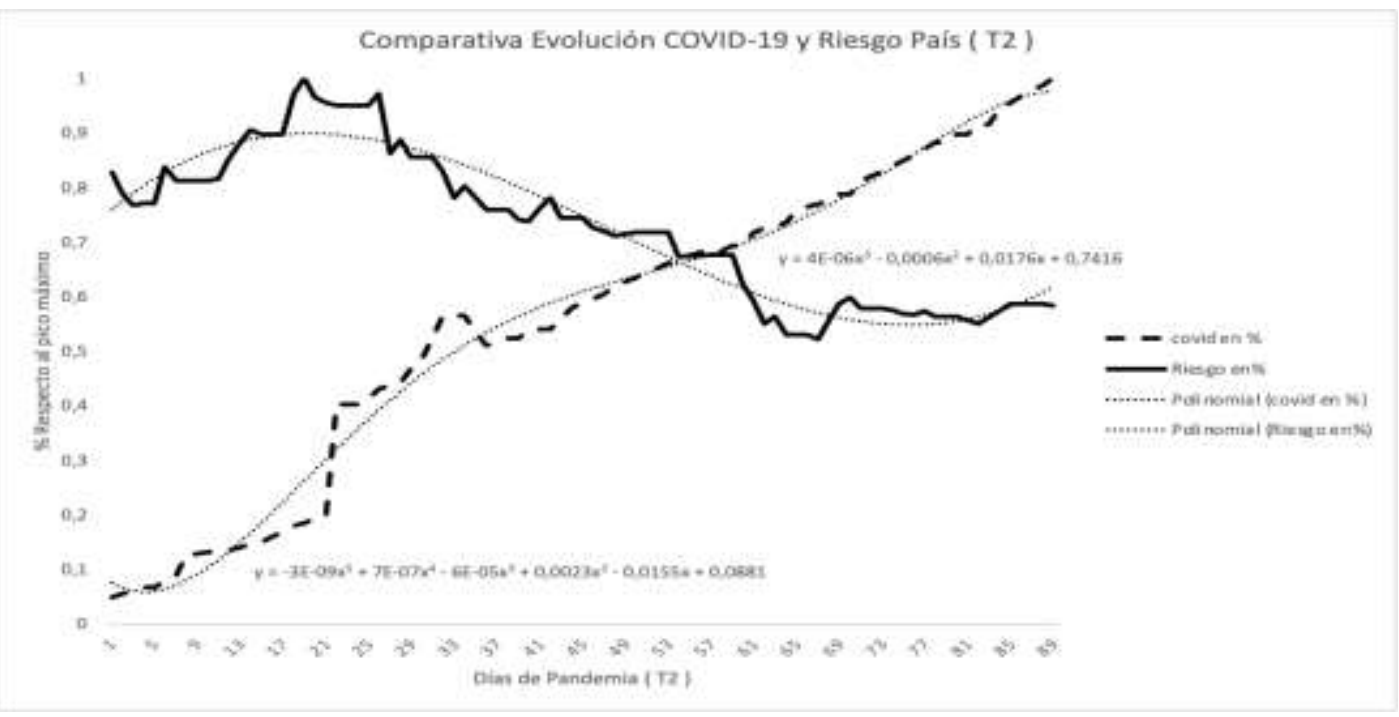

Fuente: Johns Hopkins University \& Medicine https://coronavirus.jhu.edu/map.html Banco Central Del Ecuador https://www.bce.fin.ec/index.php/informacioneconomica

\section{Elaborado por: Autores}

El análisis matemático de las curvas de evolución de Riesgo País y COVID 19 en el T2 arrojan ecuaciones de 3ero y 5to grado respectivamente siendo:

\section{Ecuación de Curva de Tendencia de Riesgo País T2}

$y=4 E-06 x^{3}-0,0006 x^{2}+0,0176 x+0,7416$

\section{Ecuación de Curva de Tendencia de casos COVID-19 T2}

$y=-3 E-09 x^{5}+7 E-07 x^{4}-6 E-05 x^{3}+0,0023 x^{2}-0,0155 x+0,0881$

En el T3 hay un crecimiento del 38\% de los casos COVID-19 llegando al cierre del T3 a 137047 casos y el Riesgo País se coloca en 16\% tendiente a la baja con 1015 puntos 
estabilizando su valor a lo largo del todo el T3. Se explicó con teoría de comportamiento e información de la población.

\section{Figura 9}

Comparativa evolución COVID-19 VS Riesgo País (T3)

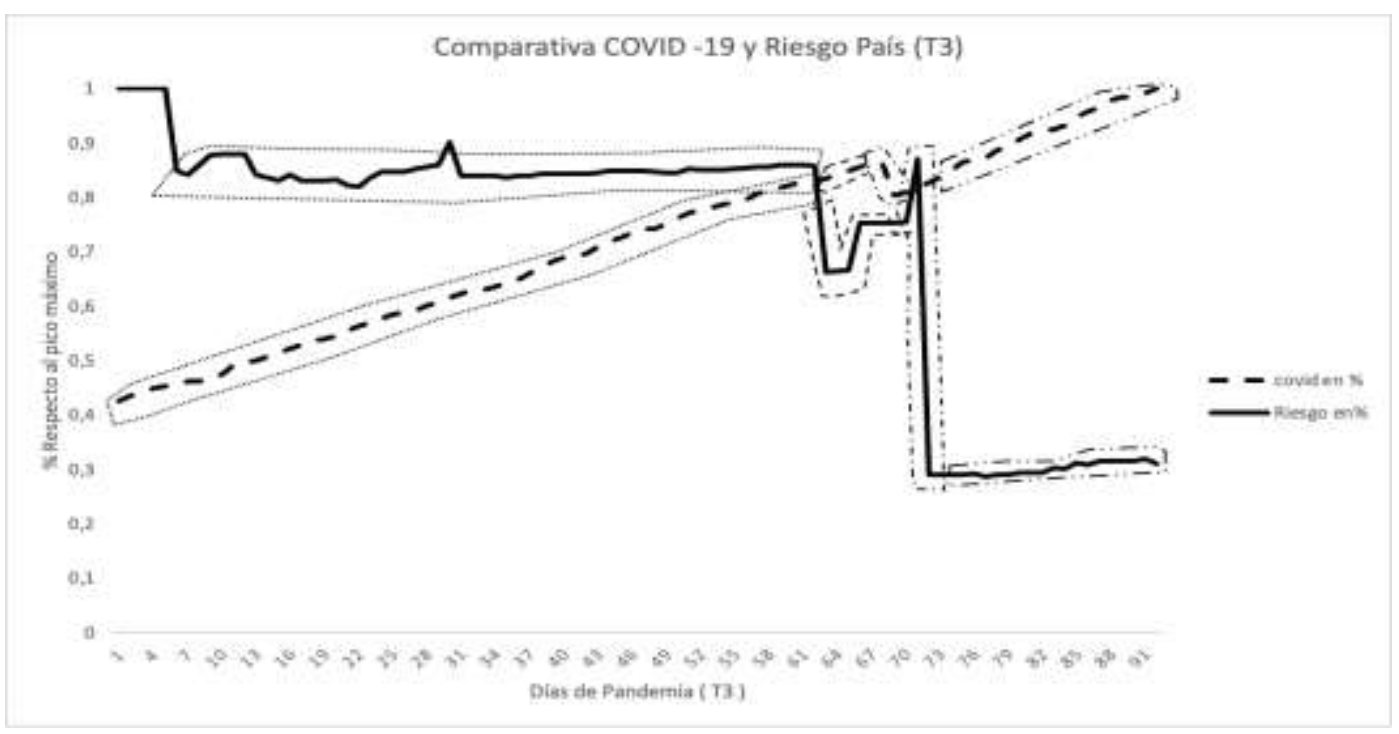

Fuente: Johns Hopkins University \& Medicine https://coronavirus.jhu.edu/map.html

Banco Central Del Ecuador https://www.bce.fin.ec/index.php/informacioneconomica

\section{Elaborado por: Autores}

Zona 1 (línea “...........")

En la zona morada en el dato 62 ( 31 de agosto) se identifica un crecimiento lineal de los casos COVID-19 que representan el 37\% con respecto al pico máximo y el Riesgo País es estable con un ligero crecimiento del $1 \%$.

Zona 2 (línea “---------“)

En la zona verde en el dato 68(6 de septiembre) se observa que existe un crecimiento lineal de COVID-19 del 4\% y una subida del 1\% del Riesgo País con un pico bajo de 20 puntos.

Zona 3 (línea “_._-_._._.“)

En esta zona hasta el dato 73 ( 11 de septiembre) se evidencia una caída de casos de COVID-19 del 6\% mientras que el Riesgo País tiene una caída del 57\%

Zona 4 (línea “..._.._.......")

En la zona tomate hasta el dato 92(30 de septiembre) presenta un crecimiento lineal de casos de COVID-19 del 20\% y el Riesgo País es estable con un ligero crecimiento del $1 \%$ 
Figura 10. Determinación de Curvas de Tendencias (T3)

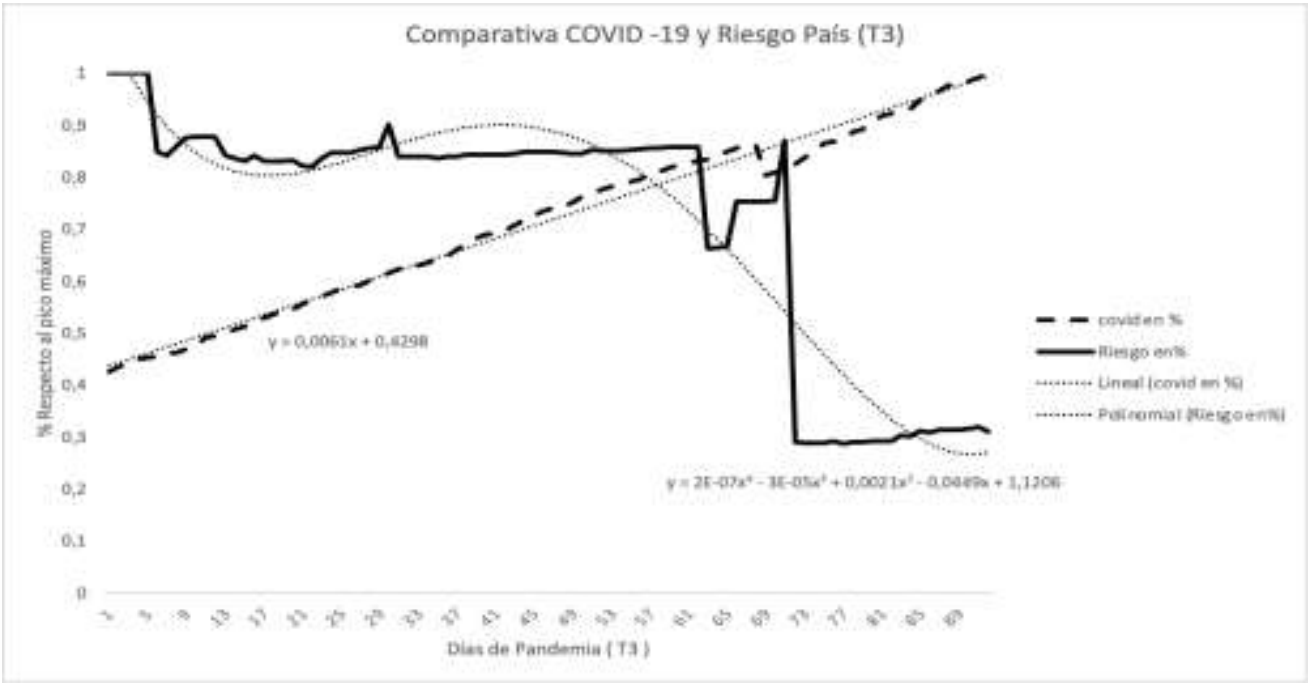

Fuente: Johns Hopkins University \& Medicine https://coronavirus.jhu.edu/map.html Banco Central Del Ecuador https://www.bce.fin.ec/index.php/informacioneconomica

Elaborado por: Autores

El análisis matemático de las curvas de evolución de Riesgo País y COVID 19 en el T3 arrojan ecuaciones de 4to y 1er grado respectivamente siendo:

\section{Ecuación de Curva de Tendencia de Riesgo País T3}

$\mathrm{y}=2 \mathrm{E}-07 \mathrm{x}^{4}-3 \mathrm{E}-05 \mathrm{x}^{3}+0,0021 \mathrm{x}^{2}-0,0449 \mathrm{x}+1,1206$

\section{Ecuación de Curva de Tendencia de casos COVID-19 T3}

$\mathrm{y}=0.0061 \mathrm{x}+0.4298$

Figura 11. Comparativa evolución COVID-19 VS Riesgo País (T4)

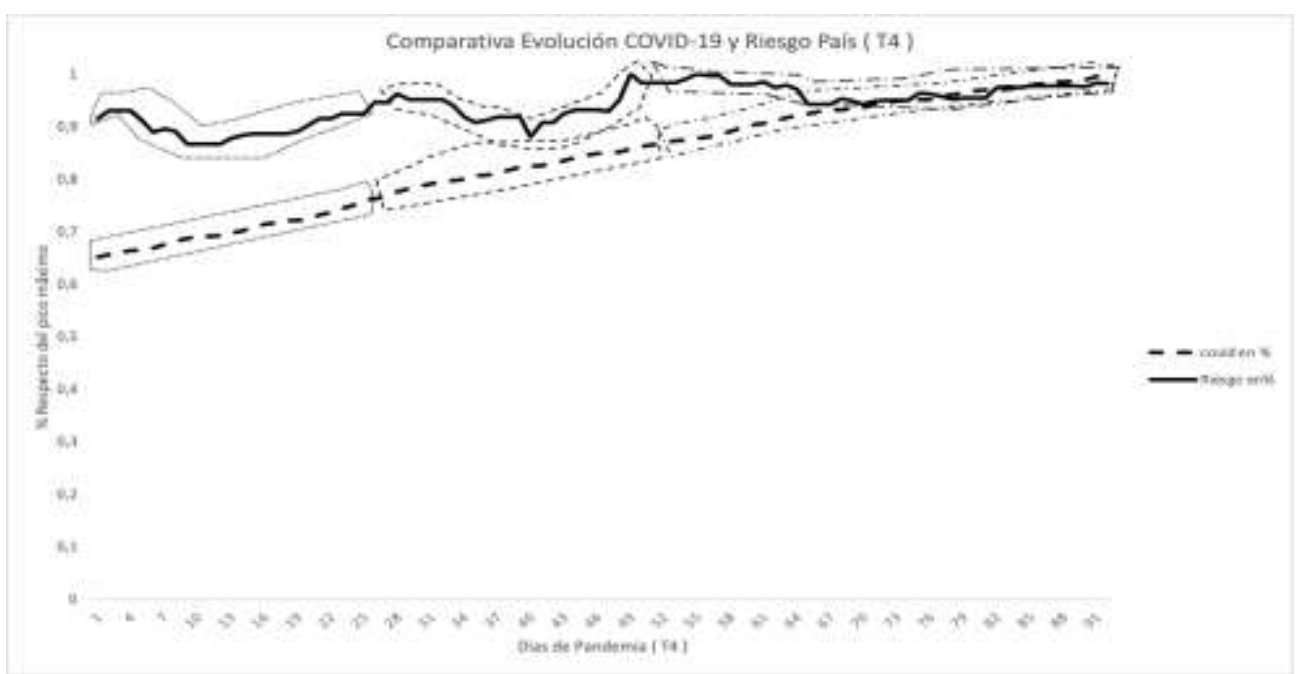

Fuente: Johns Hopkins University \& Medicine https://coronavirus.jhu.edu/map.html Banco Central Del Ecuador https://www.bce.fin.ec/index.php/informacioneconomica Elaborado por: Autores 
En el T4 los casos de COVID-19 llegaron a 1212512 y Riesgo País a 1062 punto al cierre del año y por ende del T4, lo cual representa un creciente incremento del $36 \%$ de casos COVID-19 y el Riesgo País se mantiene en el 17\% con respecto del pico más alto en este T4.

Zona 1 (línea “.

En la zona morada hasta el dato 28 (28 de octubre) se puede observar un crecimiento del 12\% en casos de COVID-19 por consiguiente el Riesgo País hay un crecimiento del 3\% y un valle de 8 puntos.

Zona 2 (línea “---------“)

En esta zona se visualiza en el dato 49 (18 de Noviembre) un crecimiento lineal de casos de COVID-19 con el 7\% y con el Riesgo País hay un crecimiento del 4\% y un valle de 12 puntos.

Zona 3 (línea “.........”)

En esta zona en el dato 92 ( 31 diciembre) existe un crecimiento lineal de casos de covid de un $15 \%$ con un Riesgo País muy estable con una bajada de a penas el $2 \%$ con respecto al pico máximo.

\section{Figura 12}

Determinación de Curvas de Tendencias (T4)

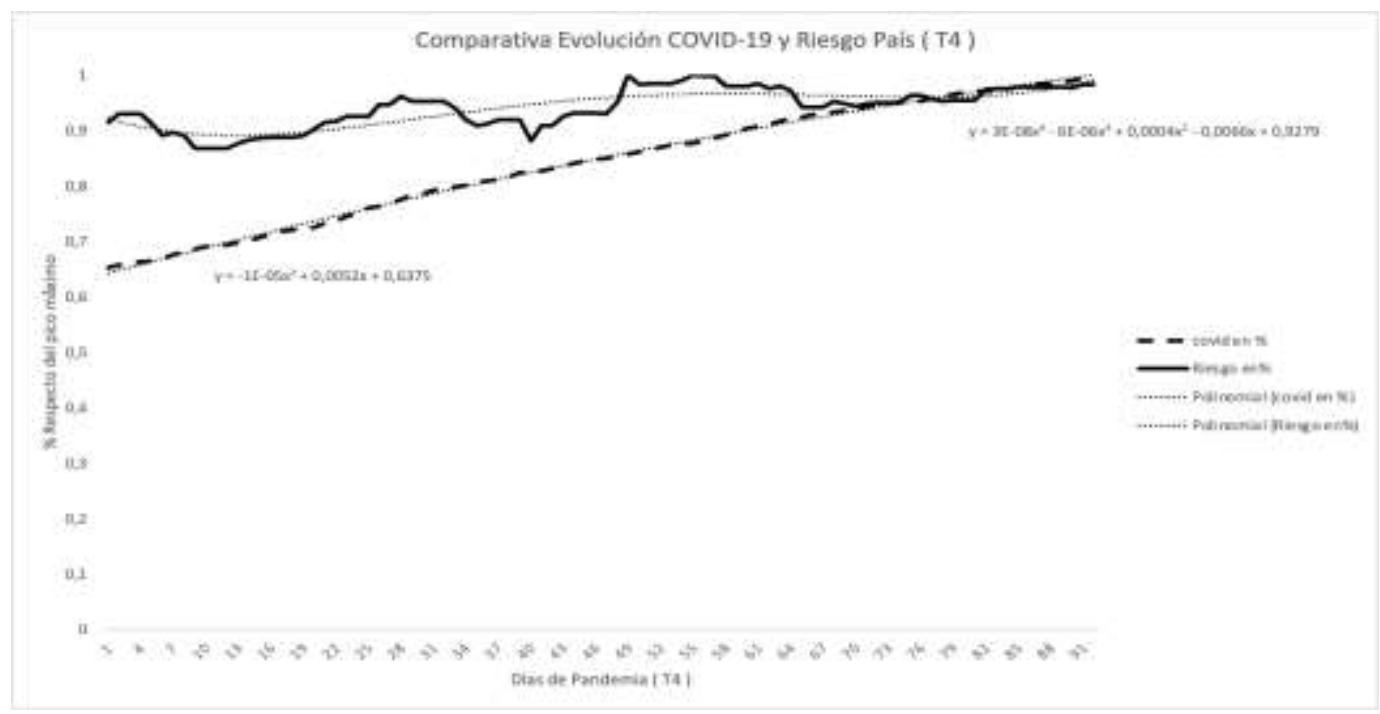

Fuente: Johns Hopkins University \& Medicine https://coronavirus.jhu.edu/map.html

Banco Central Del Ecuador https://www.bce.fin.ec/index.php/informacioneconomica

Elaborado por: Autores 
El análisis matemático de las curvas de evolución de Riesgo País y COVID 19 en el T4 arrojan ecuaciones de 6to y 1er grado respectivamente siendo:

\section{Ecuación de Curva de Tendencia de Riesgo País T4}

$y=2 E-11 x^{6}-7 E-09 x^{5}+8 E-07 x^{4}-4 E-05 x^{3}+0,0012 x^{2}-0.0153 x+0.9494$

\section{Ecuación de Curva de Tendencia de casos COVID-19 T4}

$y=0.0039 x+0.6577$

\section{Figura 13}

Puntos atípicos de las variables en estudio

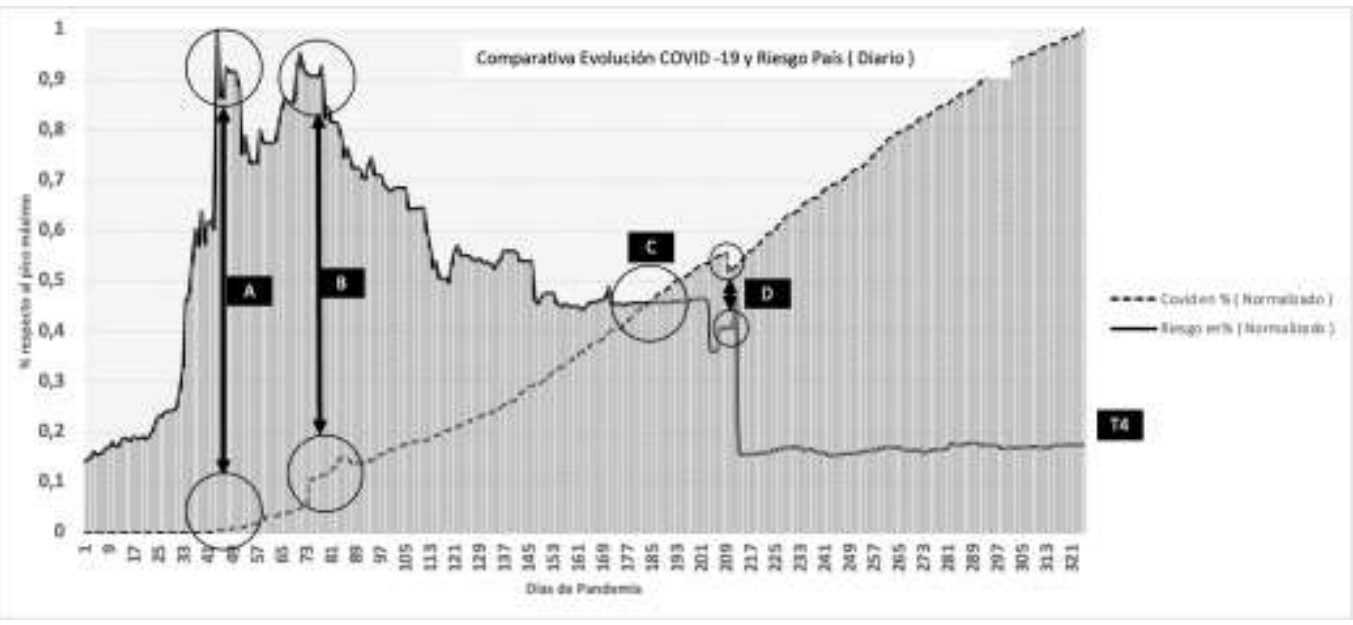

Fuente: Johns Hopkins University \& Medicine https://coronavirus.jhu.edu/map.html

Banco Central Del Ecuador https://www.bce.fin.ec/index.php/informacioneconomica

\section{Elaborado por: Autores}

Punto A: El primer pico de Riesgo País que se detecta es en el periodo 18 al 30 de marzo del 2020 con 6063 puntos en el día 23 de marzo coincidente con inicio de 981 casos de COVID-19 en el Ecuador.

Situación coyuntural:

- Caída del precio del petróleo en marzo de usd55,49 a usd33,91 y cierra el mes de marzo en usd20.30 (Datosmacro.com, 2020)

- Medidas sanitarias, económicas no estructuradas de cara al inicio de la pandemia.

- OMS declara pandemia mundial, caída de índices bursátiles en USA, al 23 de marzo S\&P500 2237.24 (Investing.com, s.f.), NASDAQ 7006.92, (Bolsamania, s.f.), DOW JONES 185.95 (Investing.com, s.f.) 


\section{Figura 14}

Dow Jones 23 de Marzo 2020

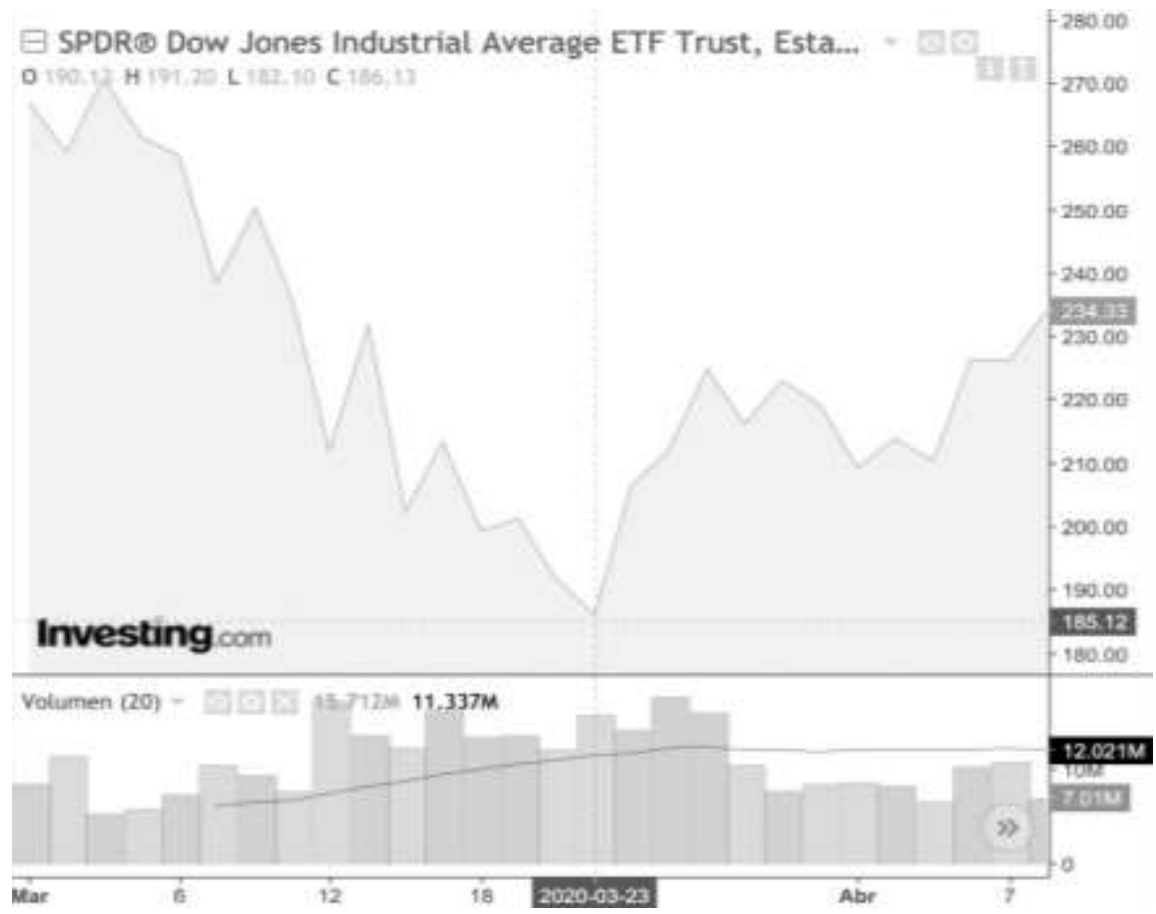

Fuente: https://es.investing.com/indices/us-30

\section{Figura 15}

NASDAQ 10023 de Marzo 2020

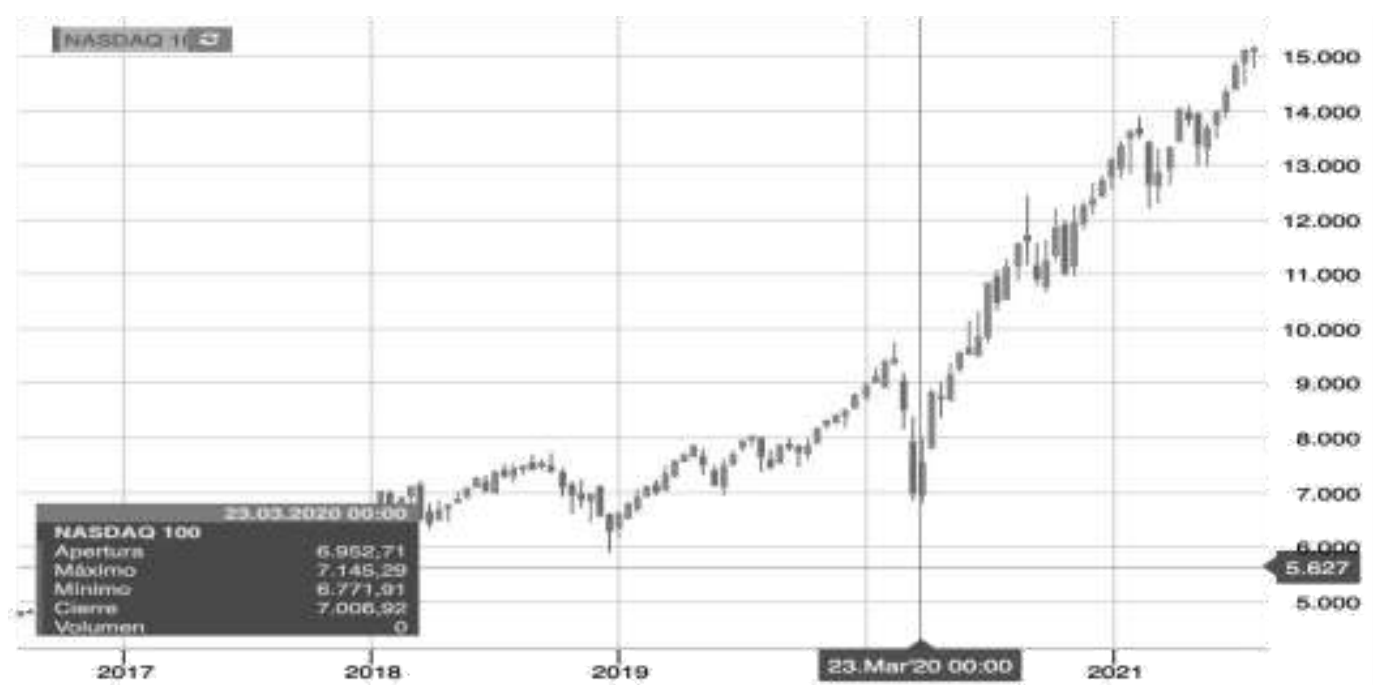

Fuente: https://es.investing.com/indices/nq-100-futures 
Figura 16. $S \& P 50023$ de Marzo 2020

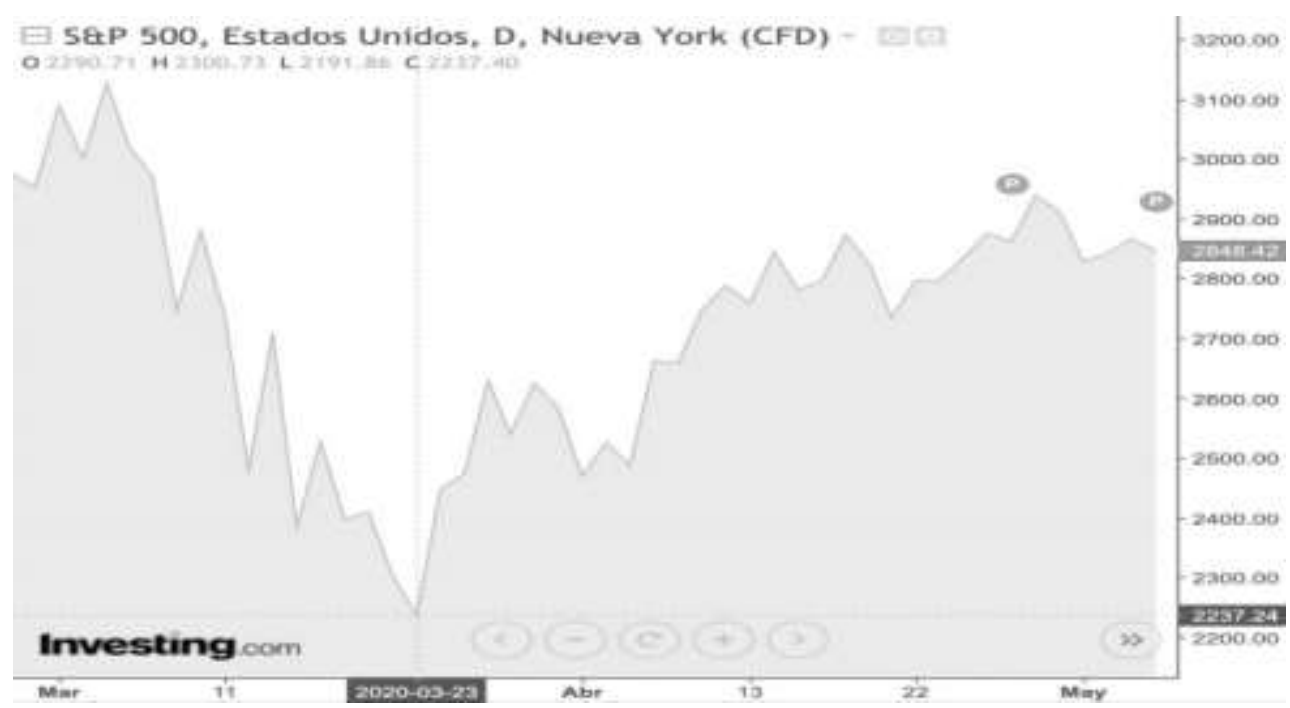

Fuente: https://es.investing.com/indices/us-spx-500-chart

Punto B: Segundo pico identificado es en el periodo 20 de abril al 6 de mayo del 2020, Riesgo País se ubica en una media de 5212 puntos y 31881 casos de COVID-19 al 6 de mayo, en el Ecuador.

Situación coyuntural:

- Caída del precio de petróleo llegando a ser NEGATIVO USD-37.63, su nivel más bajo en la historia. (El Comercio, s.f.)

- Hay un repunte de casos COVID-19 por desconocimiento de medidas de prevención, tratamiento y formas de contagio.

Figura 17. Precio del petróleo 20 de Abril 2020

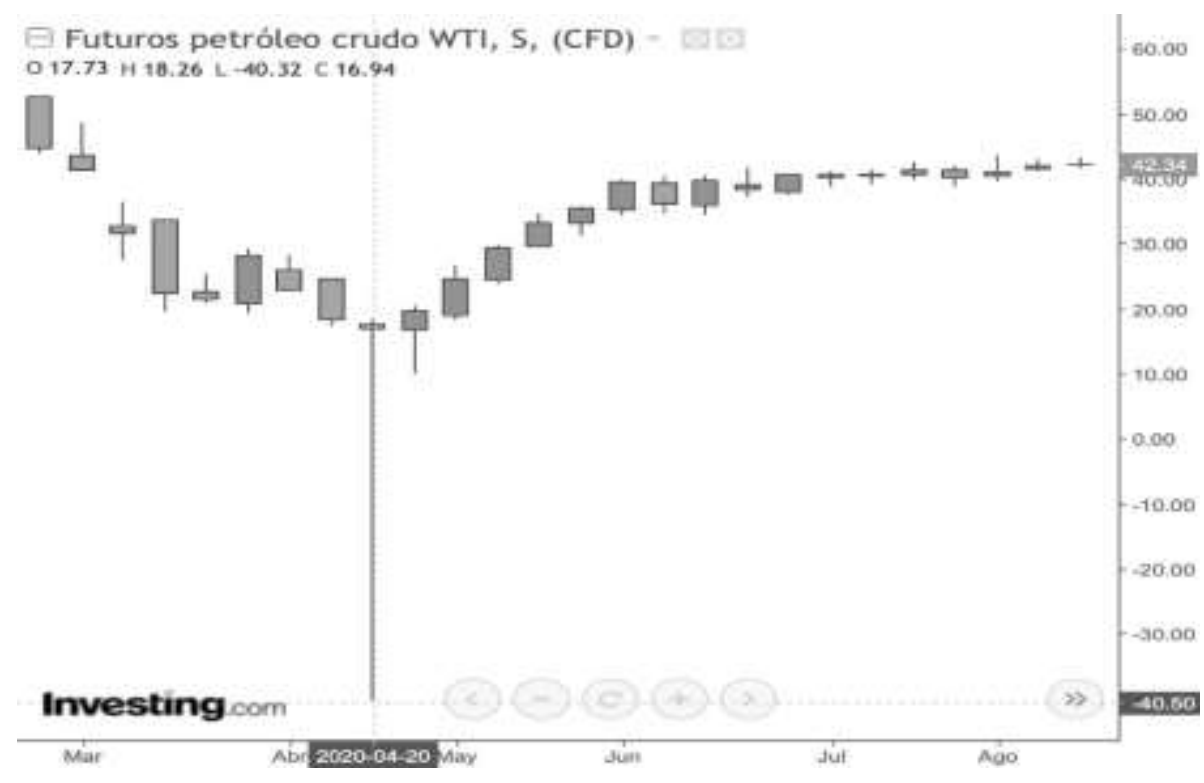

Fuente: https://es.investing.com/commodities/crude-oil-streaming-chart 
Punto C: Tercer pico identificado es el 12 de agosto del 2020, en el cual se detecta el punto de cruce entre el Riesgo País y los casos de COVID-19, el Riesgo País y COVID19 se encuentran en el $45.7 \%$ de su punto máximo. Riesgo País se ubica en 2772 puntos y 97110 casos de COVID-19 al 12 de agosto, en el Ecuador.

Situación coyuntural:

- Inicia una etapa de estabilización del Riesgo País en un promedio de 2767 puntos.

- El precio del petróleo tiende a subir ubicándose en USD42.60 al 12 de agosto 2020

- Los casos de COVID-19 se mantienen en crecimiento lineal.

Punto D: Cuarto pico identificado es en el periodo del 3 al 10 de septiembre del 2020, en el cual se evidencia una caída de los casos COVID-19 y Riesgo País, desplomándose el Riesgo País de 2468 puntos a los 952 puntos, lo que representa una caída del 25\% con respecto al pico máximo, siendo coincidente con una reducción de los casos COVID-19 de 117175 a 110757 lo que representa un 3\% con el respecto al pico máximo.

Situación coyuntural:

- Precio del petróleo se recupera en una media de USD40.00 en el mes de septiembre 2020.

- Se solicita pruebas de PCR para ingreso al país vía aérea e inicia la economía a fluir de manera más confiable hacia afuera y por ende el riesgo país tiende a bajar.

- Se reestructura las resoluciones del COE a favor de la generación de la reactivación del aparato productivo, se incrementa el aforo al 50\%, reapertura progresiva de balnearios, apertura de gimnasios y competencias deportivas, entre otros. (Servicio Nacional de Gestión de Riesgos y Emergencias, s.f.)

- Se inicia el proceso de plan piloto para inicio de clases presenciales en ciertas instituciones educativas.

\section{CONCLUSIONES}

El Riesgo País, indicador macroeconómico comúnmente utilizado como barómetro de la economía, éste en el 2020 en Ecuador, se vio altamente influenciado no solo en sus valores pico sino también en sus tendencias de comportamiento, siendo las mismas coincidentes con las tendencias y comportamientos de la COVID-19, afianzado esto en modelos matemáticos que lo demuestran.

En lo coyuntural, la economía ecuatoriana se vio afectada directamente con las medidas aplicadas por la restricción dadas por el COE Nacional en torno a la evolución de la 
pandemia COVID-19, impactando drásticamente a la capacidad de responder a las obligaciones que el país mantenía con los organismos multilaterales a nivel nacional e internacional, sectores públicos y estratégicos del aparato productivo, ocasionando problemas de riesgo y de alto impacto en la sociedad como es el desempleo, quiebre de negocios, inseguridad, insalubridad, entre otros.

Como país, es importante que se pueda contar con protocolos de riesgos proactivos ante emergencias naturales, de salud y otras que permitan tener tiempos de reacción inmediatos, la pandemia ha sido una muestra de las repercusiones económicas, empresariales, de salud y otras que han impactado nefastamente la realidad de los ciudadanos y no solo a nivel país sino a nivel mundial.

La coyuntura nacional Ecuador 2020 y el comportamiento de la sociedad ante un fenómeno mundial, como lo es la COVID-19, es explicable mediante modelos matemáticos que dan como resultado tres tipos de comportamiento y su incidencia en la economía de un país a través del indicador macroeconómico Riesgo País, sin embargo, existen otros indicadores macroeconómicos que tienen correlación con estos tipos de comportamientos a ser analizados en un futuro.

\section{LISTAS DE REFERENCIAS}

Acosta, A. (2020). EL CORONAVIRUS EN LOS TIEMPOS DEL ECUADOR.

Bernal, Á. F., Burgos Salazar, S. a., Solórzano, S. E., \& Cantos, M. d. (s.f.). La economía de las empresas del Ecuador en el contexto de la pandemia .

$\begin{array}{llll}\text { Bolsamania. } & \text { (s.f.). } & \text { Obtenido de }\end{array}$ https://www.bolsamania.com/indice/NASDAQ-100/historico-precios

Castro, C. R., Castañeda, Z. F., Ruiz Molina, K. d., González, G., \& Poveda Burgos, G. (s.f.).

Chase, R., Jacobs, R., \& Aquilano, N. (2009). Administración de Operaciones. México DF: McGraw-Hill.

Correa, R., Izquierdo Montoya, L., \& García Vélez, D. (2020). Impacto del COVID-19 en Ecuador.

Datosmacro.com. (2020). Expansión. Obtenido de https://datosmacro.expansion.com/materias-primas/opec?dr=2020-03 
EL COMERCIO. (24 de 04 de 2020). EL COMERCIO. Obtenido de https://www.elcomercio.com/actualidad/politica/ecuador-normalidaddistanciamiento-social-coronavirus.html

$\mathrm{E}$

Comercio.

(s.f.).

elcomercio.com.

Obtenido

de

https://www.elcomercio.com/actualidad/mundo/desplome-precio-petroleo-texascovid19.html

Investing.com.

(s.f.).

es.investing.com.

Obtenido

de

https://es.investing.com/etfs/diamonds-trust-chart

Investing.com. (s.f.). Investing.com. Obtenido de https://es.investing.com/indices/us-spx500-chart

Martínez De Lejarza, J., \& Martínez de Lejarza, I. (1992). Probabilidad y Modelos de Estadística Empresarial. Valencia: G.P.

Ordóñez, D. P., Campuzano Vásquez, J. A., Vega Jaramillo, F. Y., \& Luna Romero, Á. E. (2020). Crísis Económica y COVID-19 en Ecuador: Impacto en la Exportaciones.

Precio Petróleo Punto.net. (s.f.). Precio Petróleo Punto.net. Obtenido de https://www.preciopetroleo.net/precios-del-petroleo-2020-1er-trimestre.html

PrecioPetroleo.net. (s.f.). Preciopetroleo.net. Obtenido de https://www.preciopetroleo.net/wti-marzo-2020.html

Primicias. (s.f.). Primicias. Obtenido de https://www.primicias.ec/noticias/sociedad/7septiembre-ecuador-covid-contagios/

$\begin{array}{llll}\text { PRIMICIAS. } & \text { (s.f.). PRIMICIAS. Obtenido de }\end{array}$ https://www.primicias.ec/noticias/sociedad/ecuador-covid-fallecidos-contagios12-agosto/

Render, B., \& Heizar, J. (2014). Principios de Administración de Operaciones (Novena ed.). México: Pearson.

Sánchez, A. M., Vayas, T., Mayorga, F., \& Freire, C. (2021). Riesgo País Ecuador. Ambato, Tungurahua, Ecuador.

Secrataría General de la Presidencia. (s.f.). El presidente Lenín Moreno decreta Estado de Excepción para evitar la propagación del COVID-19. Obtenido de https://www.comunicacion.gob.ec/el-presidente-lenin-moreno-decreta-estadode-excepcion-para-evitar-la-propagacion-del-covid-19/ 
Reyes Pacheco y Valencia Narváez...

Servicio Nacional de Gestión de Riesgos y Emergencias. (s.f.). https://www.gestionderiesgos.gob.ec/. Obtenido de https://www.gestionderiesgos.gob.ec/resoluciones-coe-nacional-1-deseptiembre-2020/

Vásquez Lafebre, L., Quevedo Vásquez, J., Prado Pinzón, L., \& Quevedo Barros, M. (3 de julio-septiembre de 2020). COVID-19 y sus efectos en el comercio internacional. Caso Ecuador. 6.

Vinueza, P. (22 de Octubre de 2016). CCG-UNAM, V0.7. Obtenido de http://www.ccg.unam.mx/ vinuesa/ 